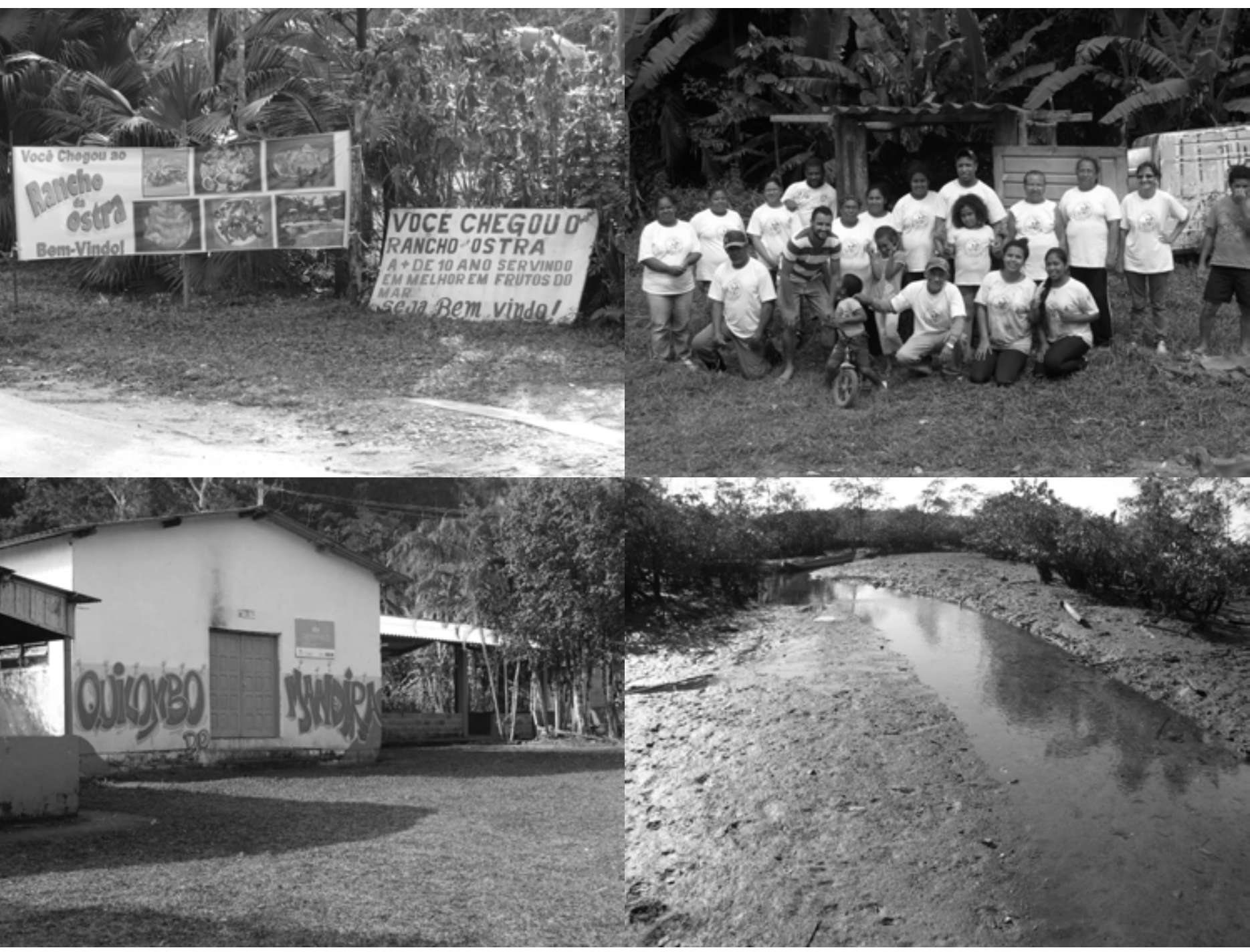




\section{MANIFESTO QUILOMBOLA}

\section{Diego de Matos Gondim}

\section{comunidade quilombola Mandira filosofia da diferença etnomatemática}

A vida aqui é assumida em sua potência de afirmação enquanto forma de resistência e constituição em oposição aos modos de falsificação e embrutecimento da vida. Assume-se uma escrita antropofágica como expressão do "fazimento" de uma comunidade quilombola no interior do estado de São Paulo.

\section{Nota ao leitor}

Este texto foi produzido junto a uma pesquisa realizada no mestrado, entre os anos de 2015 e 2018, e com uma pesquisa de doutorado que está em andamento. A produção dos dados aqui apresentados ocorreu junto a uma imersão na comunidade quilombola do Mandira, em Cananeia, no interior do estado de São Paulo. Ressalto, além disso, que a escrita deste texto não busca estabelecer conclu-
QUILOMBOLA MANIFEST | Life here is assumed in its potency of affirmation as a form of resistance and constitution in opposition to the modes of falsification and brutalization of life. Anthropophagic writing is assumed as an expression of the "work" of a quilombola community in the interior of the State of São Paulo. | Quilombola community, Mandira, philosophy of difference, ethnomathematics.

sões e verdades absolutas quando à questão quilombola, mas produzir um "manifesto" quilombola, ao modo de Oswald de Andrade, expressando, assim, uma ética, uma estética, uma política e uma economia dessa comunidade em sua busca pelo reconhecimento, demarcação e titulação de suas terras. Em outras palavras, o texto não busca "enquadrar-se" nos moldes acadêmicos na realização de um exercício exegético do ponto de vista teórico, epistemológico, filosófico etc., mas operar com rastros de um quilombo a partir de algumas vozes distribuídas na dissertação de mestrado em questão em forma de entrevistas.

O texto opera com algumas imagens produzidas durante a pesquisa de campo. Aqui, no entanto, elas não assumem uma função de representação do campo ou mesmo da própria comunidade quilombola em destaque, mas, ao contrário, elas são possibilidades de os leitores experimentarem o quilombo a partir de seus signos, ou seja, as imagens são aqui possibilidades outras de entrar nas relações do quilombo por uma via que não seja narrativa e representativa, mas operativa. Além disso, acrescento que foi publicada uma versão-ensaio, ainda que esta assim continue sendo, nos Anais do XXII Encontro Brasileiro de Estudantes de Pós-Graduação em Educação Matemática, de 2018, sob o 
título "SÓ ME INTERESSA O QUE NÃO É MEU. Lei do Homem. LEI DO ANTROPÓFAGO". " Esta versão, porém, além de acrescentar as discussões e problematizações realizadas no GT 11 - Filosofia da Educação Matemática, traz algumas outras contribuições inferidas por leitores do texto nos grupos de pesquisa dos quais o pesquisador é membro que, no entanto, foram suprimidas na apresentação do evento aqui citato, de acordo com suas exigências.

Por fim, ressalto que as citações feitas em modo de Gêneses são falas de entrevistas transcritas dos quilombolas do Mandira, para a constituição da dissertação de mestrado aqui citado. Além disso, este texto, apesar de caráter abrangente, situa-se dentro de uma área de pesquisa, a Educação Matemática, com foco na Etnomatemática. Reafirmo, no entanto, que o objetivo do texto é operar com as vozes do quilombo, constituindo, assim, uma "narrativa" dos modos como esses quilombolas se constituem enquanto comunidade. Em outras palavras, o objetivo, aqui, é operar com as entrevistas como uma forma de vida que não necessita de um plano teórico para os legitimar... Eles atravessam o texto como um movimento antropofágico, sem pedido de permissão para entrada e para saída; apenas passam, compõem a narrativa e seguem o fluxo.

Equação i: Gêneses 2: I-3 "Tem muitos políticos querendo quebrar a lei da Constituição de 1988. 2 Querem fazer com que o título seja individual. 3 Ter o título individual facilita para quem tem o poder pra comprar as terras dos quilombolas". ${ }^{2}$

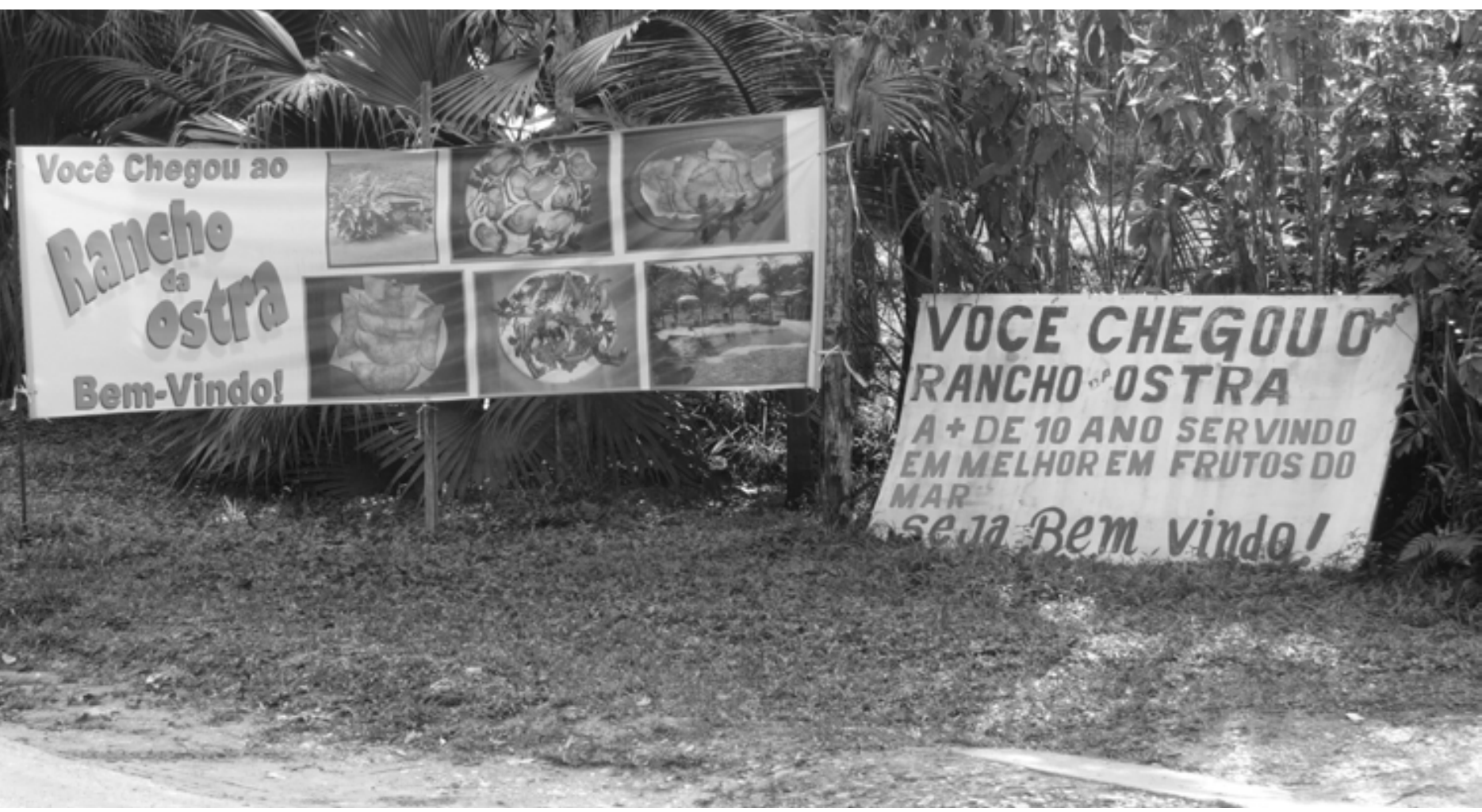


Demonstração: Um manifesto como este se constitui como um gesto de expressão: um grito, ou, como cantou Clara Nunes, "um soluçar de dor no canto do Brasil". Ele é, antes de qualquer coisa, uma reivindicação. Depois, um convite. Você chegou.

Equação ii: "Só a antropofagia nos une. Socialmente. Economicamente. Philosophicamente". ${ }^{3}$

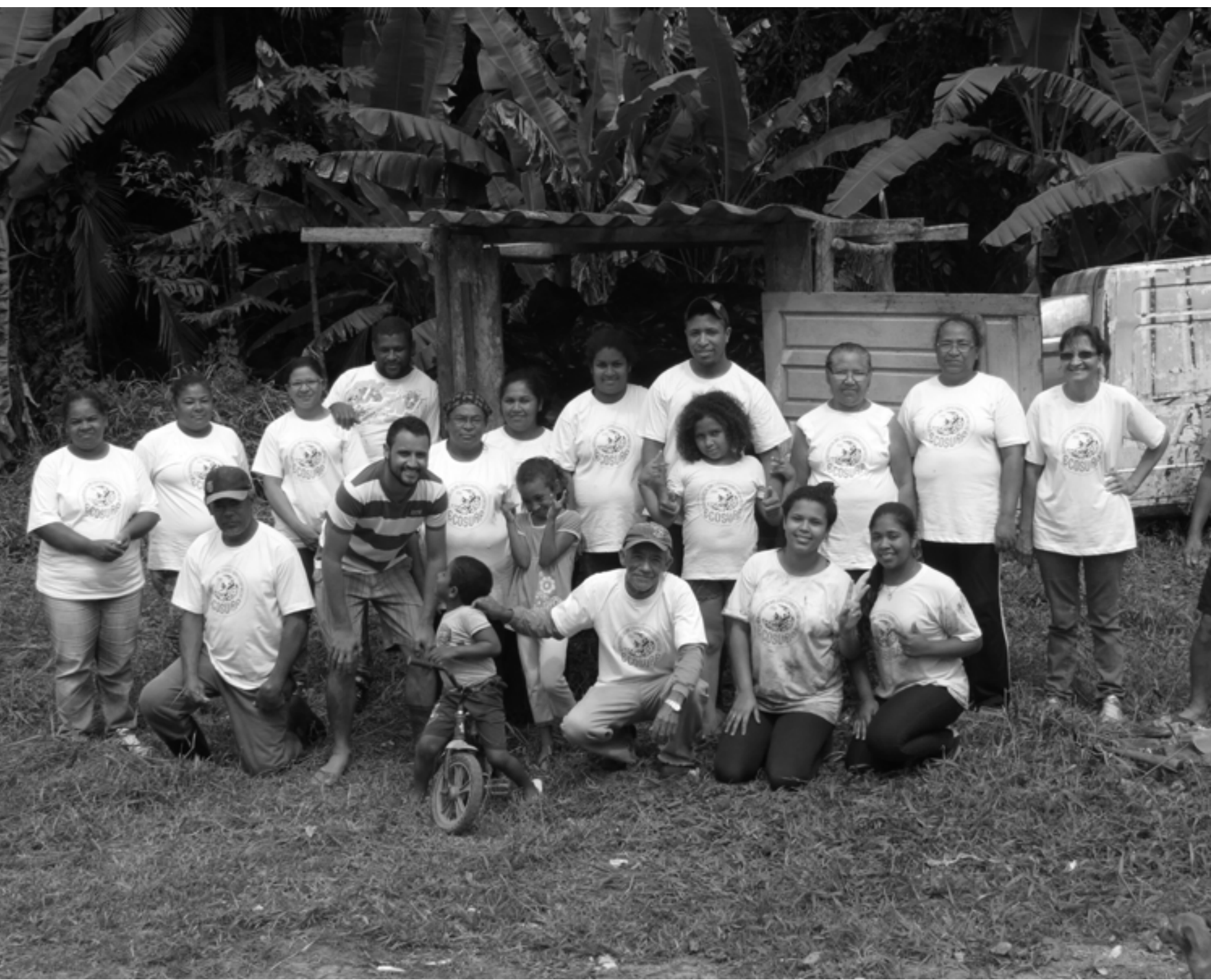

Demonstração: Uma união antropofágica não é feita, apenas, de filiações, mas também de alianças. É um conjunto de alianças, de povoamentos, de multidões. Longe de ser unitário. 
Equação iii: "Não é mais a afirmação de uma substância única, é a exposição de um plano comum de imanência em que estão todos os corpos, todas as almas, todos os indivíduos". ${ }^{4}$

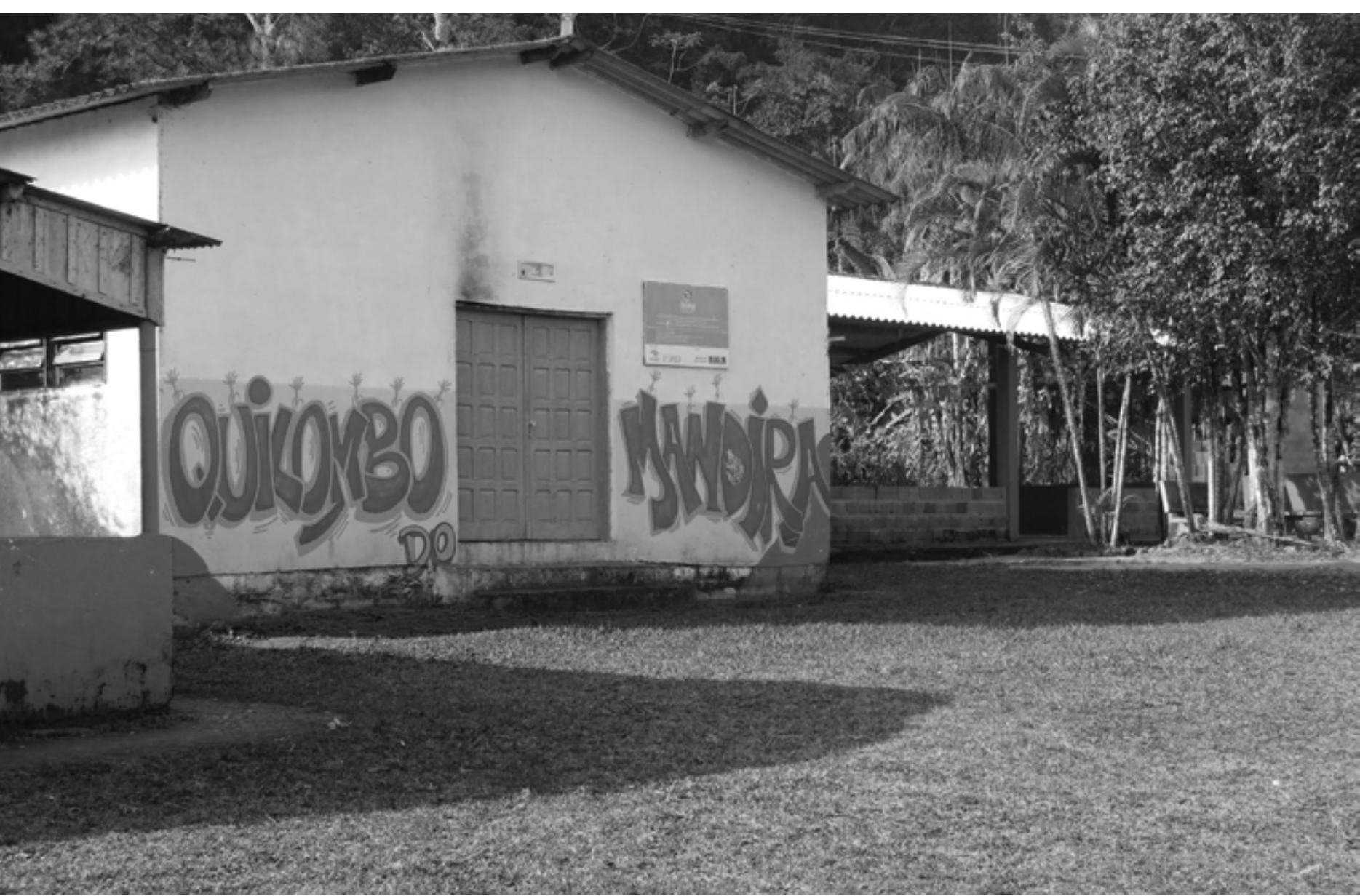

Demonstração: Um plano comum de imanência é um conjunto de práticas. Atravessado por uma união antropofágica, é um plano de distribuição das forças, dos afectos, das subjetivações, das individuações... Longe de ser absoluto. 
Filhos de João, que é filho negro de Francisco, irmão de Celestrina, que são filhos de Antônio...

Parece-me que estão reunidas aqui as condições para que se desenvolva uma espécie de máquina imensa, uma espécie de imenso cíclotron de produção de subjetividades mutantes. ${ }^{6}$

Gêneses 14:2-4 "Tinha algumas pessoas que moravam lá, mas consideravam-se todos irmãos. 3 Não eram donos do Mandira, mas tinham o direito de trabalhar. 4 Muitas pessoas morou lá, cresceu, construiu casa, criou seus filhos lá...". ${ }^{7}$ Contra as políticas das propriedades privadas. Contra as porteiras dos grandes fazendeiros, dos acumuladores de posses, dos colonizadores de terras férteis. Assim respondeume um, comi-o. Antropófago!

O direito que une não é o direito da posse, mas o direito de trabalhar. Uma irmandade constituída na aliança. Trabalhar: ...e plantar e caçar e colher e viver e... Documentos atestam a constituição de uma Communauté, em termos legais, entre as décadas de 1970 e 1990. Comunidade Legal. Porém, antes mesmo da Lei Áurea, "o negro do Mandira já era liberto, pois tinha recebido a terra como herança" (Gêneses I: I2). ${ }^{8}$ Herança de um trabalho partilhado. Mandira é nome de muitas gentes. Antropófagos!

Filhos de Antônio Florenço de Andrade, dono da fazenda de arroz. Francisco, filho da escrava, bastardo de Antônio. Celestrina, mulher, filha de Antônio, irmã branca de Francisco. Sejam bem-vindos à fazenda Mandira. Localizada em Cananeia, cidade ilustre de Pindorama (ou, do Brasil) - primeira cidade do Brasil?! - , sitiada pelo Valo Grande. ${ }^{9}$

Celestrina, que foi embora para as Gerais em busca de ouro, doou suas terras a seu meio-irmão, Francisco. Como meio-irmão, ele é também meio de passagem. Meio de afirmação. Meio que arras- ta as margens para um fluxo contínuo de différence. Em oposição às origens a resgatar. Não há origens a recuperar, apenas cortes de uma immanence. Para além da filiação, um meio-irmão é garantia de aliança, de novos possíveis.

Francisco, que casou, foi pai de vários filhos. Desses, ficaram João e Antônio, dois filhos de Francisco. Gêneses I: 3 "João era um negro superinteligente, muito inteligente. 2 Ele aprendeu a ler e a escrever em casa. 3 Naquela época não tinha escola; Celestrina sabia ler (porque era branca) e ensinou o Francisco que ensinou a seus filhos". ${ }^{10}$ Antropófago, só the interessa o que não é seu. Filho negro comeu irmã branca. Comeu o direito da possibilidade, a leitura. Uma inteligência antropofágica não da ordem da devoção, mas da "devoração".

João e Antônio, filhos do filho da escrava, dividiram uma terra sem nomes, sem documento, tudo "no fio do bigode", "você fica para lá e eu fico para cá", disse-me um outro, comi-o. João era João, Antônio era Antônio, uma singularidade. Viviam da roça de subsistência. Gentes chegavam, "não eram donos, mas tinham o direito de trabalho". Bem-vindos ao Mandira, partilhas de subsistência, subexistência. Mandira, nome de muitas gentes.

\section{Antropófagos!}

Essa irmandade, que não é constituída pela filiação como nas genealogias messiânicas, expressa um mundo não rubricado, baseado nas alianças de diferenças e não nas filiações identitárias. A constituição do Mandira enquanto quilombo é fundamentada, antes de qualquer coisa, em uma subjetividade antropofágica. Um quilombo é lei nomos em oposição ao logos, polis, falo, ego... e tudo que seja uma eterna sagração do Eu. Como canibais, comiam os que chegavam, eram comidos pelos que chegavam. Lei da antropofagia, "só me interessa o que não é meu". ${ }^{11}$ 
A "mestiçagem" se compõe com pedaços humanos e não humanos. A partilha do sensível é a linguagem da comunicação dos mundos. Cosmologias coengendram natureza e cultura, não as antagonizam. Gênesis 5: 14 "A maneira de caçar faz parte da cultura, melhor, fazia parte da cultura dos tradicionais e dos caiçaras". ${ }^{12} \mathrm{O}$ que hoje é chamado de quilombo do Mandira é esse corpo de todas línguas, humanas e inumanas, de tradicionais, caiçaras, negros e maneiras: multidões. Uma antropofagia expressa, sempre, um modo de povoar, de ocupar, de proliferar, de comunicar, em vez de um modo de ser. Predadores!

O povoamento da terra é um povoamento de multiplicidades. Mandira não expressa os prefixos "o" e "a", mas "um" e "uma". Não é $n$ (UNO), nem múltiplo $(n+1)$, mas multiplicidade $(n-1)$, contra toda dualidade. A multiplicidade é a variação de uma individuação lançada ao infinito. ${ }^{13}$ To be or not to be não é uma lógica funcional nesse tipo de subjetividade, pois ela é "um retorno ao direito materno e natural, à propriedade comum do solo e ao estado sem classes", é uma revolução (Caraíba?!). ${ }^{14}$

Uma cultura fundamentada em um modo de caçar não é uma cultura messiânica, que privilegia o patriarcado, as propriedades privadas, o acúmulo de posses, o sedentarismo como forma de vida, mas uma agilidade nômade esparsa em meio à floresta atrás de sua presa, em oposição aos códigos de conduta, aos parques de preservação do meio ambiente sem gente. Uma cultura da caça trata-se de uma "cultura antropofágica".

Contra todos os coronelismos, João e Antônio se fazem Mandira, antropófagos da terra. Contra as propriedades privadas. To be or not to be não é o que está em jogo, mas o direito de trabalho, o direito da partilha. Gêneses 3: 4-5 "Por sair defendendo terras aqui, ficou muito conhecido. 5 Há relatos que ele [João] defendeu terras de grileiros até no Paraná.". ${ }^{15}$ Lei da antropofagia: "contra as elites vegetaes. Em comunicação com o sólo". ${ }^{16}$

Gêneses 2: 7 "Hoje, no século XXI - não precisa ser negro não - pobre brigar por terra é muito difícil de ele ganhar a questão, nós sabemos; imagine naquela época, um negro ganhar uma questão dos coronéis...". ${ }^{17}$ Mas a antropofagia nos une socialmente. Uma cultura antropofágica é uma contestação em vez de uma contemplação. Mandira é nome de muitas gentes. Contra a "verdade" do mundo rubricado dos grileiros, João assina Mandira. Nome da terra, do rio que divide lados, da doação da irmã branca. João se faz homem-terra como contestação à falsificação da vida.

Gêneses 12: 5 "Então ele assinou o nome Mandira, que era o nome da fazenda". ${ }^{18}$ É por isto que, em Gêneses I: 2, "costumo dizer que [o Mandira] é um quilombo diferente de todos os quilombos do Brasil". ${ }^{19}$ Fundado por uma revolução caraíba na terra de Pindorama. Mandira não expressa o desejo por uma identidade, mas de passagem de um modo de vida, um modo de caça, um modo de ocupar a terra... Mandira é nome de passagem, é ponte para a travessia de uma multidão. Antropófagos!

Uma cultura antropofágica, em oposição à cultura messiânica, não joga na dualidade, na unidade, é sempre multiplicidade. Não importa de onde vêm... todos têm o direito de trabalhar. A política, aqui, não é da propriedade, mas da liberdade. Mandira não expressa apenas um nome, estático, escravo da diversidade, sua liberdade é da ordem da proliferação. Gêneses I2: II “Hoje os mandiranos são, aproximadamente, 1300 ou 1400 e estão em São Paulo, em Minas Gerais, no Paraná, todos espalhados". ${ }^{20}$ Como uma erva daninha, espalham(-si), multiplicam(-si)... Como caçadores, são predadores de mundos. 
A identidade é lançada a uma divisão ao infinito. É uma derivada. Uma diferenciação. Uma linha de subjetivação, pois "a antropofagia é todo o contrário de uma imagem identitária". ${ }^{21}$ Os mandiranos espalharam(-si) em mundos. O mapeamento dessas subjetivadas antropofágicas expressam uma cartografia sempre aberta, com múltiplas entradas e saídas. Esse mapa, em vez de impor o verbo "ser", opera com conjunções "e... e... e..." conectando(-si) com Paulos, com Gerais e com outros. Lei da antropofagia: multiplicar(-si).

Extra-ser. Em oposição às lógicas do Eu absoluto, cognoscente. Uma afirmação das individualités, singularités... no lugar dos privilégios antropológicos e antropocêntricos. Expressão de fissuras, rupturas... cortes de immanence. João Mandira, une individuation collective de um "instincto Carahiba". 22 Uma cultura antropofágica, atravessada por um instinto Caraíba, sacode e desterritorializa as imposições de Estado, os desejos coronelistas, as façanhas catequistas. Expressão da liberdade, de uma revolução em (e de) Pindorama. É o direito como exercício da possibilidade. Antropófagos!

Contra os regimes imagéticos das árvores-mundo, a fixação. Uma cultura antropofágica é da ordem da ocupação, distribuem-se, esfacelam(-si). Gêneses 9: 14 "Os outros todos se esfacelaram na vida". ${ }^{23}$ Mandira é da ordem da multiplicação, esfacelam(-si) em vidas, expressam(-si) um tornar(si), um vir-a-sef(-si), um devir, composta por anéis abertos, alianças antropofágicas.

Diluem as lógicas binárias sujeito ou objeto, forma ou matéria, cultura ou natureza, indivíduo ou sociedade, rural ou urbano. Contra todas as lógicas hilemórficas. É fundada em uma multiplicida de que não é sujeito nem objeto, mas dimensões de encontros. "Une multiplicité n'a ni sujet ni objet, mais seulement des déterminations, des grandeurs, des dimensions qui ne peuvent croître sans qu'elle change de nature (les lois de combinaison croissent donc avec la multiplicité)" ${ }^{24}$

Uma cultura antropofágica não privilegia a unidade, nem a variedade e sequer a diversidade. A diversidade é da ordem do mesmo. É a legitimação das genealogias messiânicas. Uma cultura antropofágica não é feita pelo reconhecimento de privilégios, mas de conexões com uma multiplicidade. "A multiplicidade não tem nada a ver com a variedade ou a diversidade. A multiplicidade é a capacidade que a diferença tem de (se) multiplicar". ${ }^{25}$ Antropofagia: uma antigenealogia.

Gêneses 14: 5 "Era um lugar que vivíamos com liberdade, tínhamos liberdade. Roçava em qualquer parte, plantava, fazia canoa em qualquer parte" ${ }^{26}$ A liberdade não está vinculada a princípios transcendentais, seu vínculo é com coisas terrenas. A liberdade é da ordem de ocupar qualquer parte. Distribuir(-si) em qualquer canto. Fazendo canoa. Plantando. Roçando. E... e... e... A liberdade é alegria, uma prova dos nove!

João Mandira perde a conotação identitária na história mandirana quando, como um personagem conceitual, torna(-si) passagem de intensidades na produção de sentidos. Ele funciona como uma inteligência antropofágica. É um estado de invenção de mundos. De transbordamento de subjetividades antropofágicas. Escapa às lógicas do Ser absoluto. Em uma cultura como essa, diferentemente da cultura messiânica, "o que temos são processos de individuação ou de subjetivação, que se fazem nas conexões entre fluxos heterogêneos, dos quais o indivíduo e seu contorno seriam apenas uma resultante". ${ }^{27}$

Gêneses 2: 3-4 "Naquela época, os coronéis do Brasil possuíam grande proporção de terra. 4 Aqui tinha um coronel chamado Coronel Cabral, grileiro; ele tinha toda esta área, desde o Itapitangui até 
Guatiçaba (já é Paraná)" ${ }^{28}$ Contra todos os nomes que viessem depois de Coronel, João assinou Mandira. Contra Cabral e a falsificação da vida, da terra. João Mandira, nascido de uma subjetividade antropofágica, Francisco, meio-irmão (negro) aquele que devorou a leitura de sua irmã branca -, ao assinar Mandira como nome, produz uma cultura antropofágica, um quilombo. Gêneses 2: 5 "O filho de Francisco, João, ia para Santos-SP brigar pelas terras do Mandira". 29

Em oposição às formas de falsificação da vida, dos mundos rubricados dos coronéis e fazendeiros, João inventa uma revolução Caraíba, um Mandira, uma multidão. Contra as políticas unitárias, totalitárias, universais, essa multidão é toda um

plano comum de imanência, uma comunidade de remanescentes quilombolas. Contra uma História Maior, inventam um plano de práticas micropolíticas e macropolíticas, que constituem uma individuação coletiva. Inventam uma união antropofágica. Uma revolução Caraíba.

Essa união, atravessada por uma inteligência que não é baseada nos modelos de recognição de Estado, expressa sua individuação coletiva como uma máquina de guerra. Em oposição às políticas de privilégios, uma união antropofágica não é vista a partir de uma filosofia, ela é, em si mesma, uma questão filosófica, por se tratar primeiro de uma questão de direito. Uma união baseada na liberdade de poder devorar o outro. O negro do Mandira já era liberto: Lei Imperial n. 3.353, sancionada em 13 de maio de $1888 .^{30}$ Essa união não reivindica privilégios, mas o reconhecimento da Constituição da República Brasileira de 1988, ${ }^{31}$ a aplicação do decreto n. 4.887, de 20 de novembro de 2003, ${ }^{32}$ a garantia de posse.

Gêneses 20: 1-9: Fomos reconhecidos pelo estado, Fundação dos Palmares, em
2002. 2 O reconhecimento, o estado faz um trabalho dentro da comunidade, do território, da sua origem. 3 Em 2015, a comunidade foi reconhecida pelo INCRA. 4 Falta o principal para nós, que o título da terra. Que garante para nós que isso aqui não será vendido. 5 Isto aqui ninguém vai poder entrar aqui dentro mais, porque é nosso. $6 \mathrm{~A}$ partir que fomos reconhecidos pelo Estado e, principalmente, pelo INCRA, a gente já pode usar o território. 7 Mesmo que o dono não queira, mas é lei. 8 Temos esse direito do território. 9 Falta o principal. Este papel garante que o título da terra vai ficar para os nossos herdeiros. ${ }^{33}$

Este manifesto quilombola reivindica uma entrada pelo quilombo do Mandira a partir de suas imagens, narrativas, desejos... Este manifesto deseja a invenção de mundos dentro de um mundo. Em oposição à inércia dos processos de identificação, reconhecimento, delimitação, demarcação e titulação das terras ocupadas por remanescentes das comunidades quilombolas, Mandira resiste ao Temps Majeur, régio. "Falta o principal", um papel, a garantia de um direito.

A resistência se constitui junto a outros coletivos, que multiplicam forças. Mandira, Reserva Extrativista do Mandira, Associação de Remanescentes Quilombolas do Mandira, Bairro Mandira, na Cidade Ilustre de Pindorama... Inventam múltiplas individuações coletivas, institucionalizadas e identitariamente reconhecidas, nem singulares, nem plurais, mas fractais, para resistir às formas de "grilar" a vida, às formas de falsificação do desejo. Se essas individuações são emergentes é porque são, também, imanentes.

Por fim, este texto reivindica a passagem de um quilombo para além dos filtros científicos, dos quereres antropocêntricos, logocêntricos, egocêntri- 
cos, e todos os "cêntricos" que regem nosso mundo. É um convite às margens do Vale do Ribeira, São Paulo, ou às Ribeiras de Vales do Mandira...

"Roteiros. Roteiros. Roteiros. Roteiros. Roteiros. Roteiros. Roteiros". ${ }^{34}$ Neste manifesto, nos opomos, também, à domesticação da escrita. Às identidades etnomatematizáveis como formas absolutas do mundo. À linearização da escrita, seja ela acadêmica, seja ela poética. Em oposição às equações e demonstrações como luz do mundo, como verdades absolutas. Reivindicamos uma escrita das intensidades, de um conjunto de práticas distribuídas em um plano comum de imanência. Contra a docilização dos corpos. Contra a redução das potências. Afirmando a irredutibilidade das individuações, das singularidades, dos afectos em imagens-equações, imagens-teoremas, imagens-demonstrações. Assumindo a imagem como uma entrada nas multiplicidades.

Deslocar todo tipo de essencialismo. O ser autêntico. A identidade genuína. O conhecimento incorrompido. O sujeito imaculado. A existência inocente. A cultura pura. A comunidade primitiva. A verdadeira democracia. O núcleo, o cerne, a essência das coisas e dos seres; sua localização no firmamento etéreo e transcendental das formas ideais. Trazer para o jogo, em vez disso, o fabricado, o construído, o inventado. Exaltar o caráter humano, profano, terreno, de nossos objetos. Assumir nossa responsabilidade na sua criação. ${ }^{35}$

Em oposição à afirmação: a matemática está em tudo, propomos: há vida em tudo!

\section{NOTAS}

1 Gondim, Diego de Matos. SÓ ME INTERESSA O QUE NÃO É MEU. Lei do Homem. LEI DO ANTROPÓFAGO.
In: Encontro Nacional de Estudantes de Pós-Graduação em Educação Matemática EBRAPEM, 22, 2018, Campina Grande. Anais... Belo Horizonte: UFMG, 2018.

2 Gondim, Diego de Matos. Ribeiras de Vales ...e experimentações e grafias e espaços e quilombolas e... Dissertação (Mestrado em Educação Matemática) - Universidade Estadual Paulista Júlio Mesquita Filho (Unesp), Rio Claro, 2018: 30.

3 Andrade, Oswald. Manifesto Antropófago. Revista de Antropofagia, n. 1, 1928: 6.

4 Deleuze, Gilles. Espinosa: filosofia prática. Tradução Daniel Lins e Fabien Pascal Lins. São Paulo: Escuta, 2002: 127.

5 Deleuze, 2002, op. cit.: 13-14.

6 Rolnik, Suely; Guattari, Felix. Micropolíticas: cartografias do desejo. 4. ed. Petrópolis: Vozes, p. 310.

7 Gondim, op. cit.: 27.

8 Gondim, op. cit.: 12.

9 Gondim, op. cit.

10 Gondim, op. cit.:22.

11 Andrade, op. cit.: 3.

12 Gondim, op. cit.: 23.

13 "quand nous employons le substantif multiplicité, nous indiquons déjà par-là que nous avons dépassé l'opposition des prédicats un-multiple, que nous sommes déjà installés sur un tout autre terrain, et sur ce terrain nous sommes nécessairement amenés à distinguer des types de multiplicités. En d'autres termes, la notion même de multiplicité prise comme substantif implique un déplacement de toute la pensée : à l'opposition dialectique de l'un et $d u$ multiple, on substitue la différence typologique entre des multiplicités" (Deleuze, Gilles. Théorie des multiplicités chez Berson. Web Deleuze. [S.I: s.n.]. Disponível em: <https://www.webdeleuze.com/ textes/107> . Acesso em: 20 mar. 2018. 1969). 
14 Schwartz, Jorge (Org.). Literatura comentada: Oswald de Andrade. 2. ed. São Paulo: Editora Nova Cultural, 1988: 141.

15 Gondim, op. cit.: 22.

16 Andrade, op. cit.: 3.

17 Gondim, op. cit.: 22.

18 Gondim, op. cit.: 27.

19 Gondim, op. cit.: 21.

20 Gondim, op. cit.: 27.

21 Rolnik, Suely. Esquizoanálise e antropofagia. In: Alliez, Éric (Org.). Gilles Deleuze: uma vida filosófica. São Paulo: Editora 34, 2000, p. 451-462.

22 Andrade, op. cit.: 22.

23 Gondim, op. cit.: 27.

24 Deleuze, Gilles. Mille Plateaux: capitalisme et schizophrénie. Paris: Les Éditions de Minuit, 1980: 14.

25 Silva, Tomaz Tadeu da. Identidade e diferença: impertinências. Educação \& Sociedade, v. 23, n. 79, 2002: 65-66.

26 Gondim, op. cit.: 27.

27 Rolnik, op. cit. 453.

28 Gondim, op. cit.: 21.

29 Gondim, op. cit.: 21.

30 Art. $1^{\circ}$ : É declarada extincta desde a data desta lei a escravidão no Brazil" (Brasil. Lei n. 3.353, de 13 maio 1988 - Lei Áurea).

31 Art. 68. Aos remanescentes das comunidades dos quilombos que estejam ocupando suas terras é reconhecida a propriedade definitiva, devendo - Estado emitir-lhes os títulos respectivos (Brasil. Constituição da República Federativa do Brasil: texto constitucional promulgado em 5 de outubro de 1988, com as alterações determinadas pelas Emendas Constitucionais de Revisão nos 1 a 6/94, pelas Emendas Constitucionaisnos 1/92 a 91/2016 e pelo Decreto Legislativo no 186/2008. Brasília: Senado Federal, 2016).

32 Brasil. Decreto n. 4.887, de 20 de novembro de 2003.

33 Gondim, op. cit.: 29-30.

34 Andrade, op. cit.: 3.

35 Corazza, Sandra M.; Tadeu, Tomaz. Manifesto por um pensamento da diferença em educação. In: Corazza, Sandra. M.; Tadeu, Tomaz. Composições. Belo Horizonte: Autêntica, 2003: 15.

Gondim é um corpo... uma imagem... uma matéria... que desliza entre arte, filosofia, educação (matemática), sempre se conjugando e... e... e... Nesse entre, é aluno de doutorado em Educação Matemática pela Universidade Estadual Paulista (Unesp), campus Rio Claro e em Filosofia pela Université Paris 8. Recebeu apoio da Coordenação de Aperfeiçoamento de Pessoal de Nível Superior (Capes) e, agora, é financiado pela Fundação de Amparo à Pesquisa do Estado de São Paulo (Fapesp), processo n. 2017/23227-1. 